\title{
Analysis and Breakdown of Overall 1-Year Costs Relative to Inpatient and Outpatient Care Among Rheumatoid Arthritis Patients Treated with Biotherapies Using Health Insurance Claims Database in Alsace
}

\author{
Morgane Beck ${ }^{1,2}$ - Michel Velten ${ }^{1}$ Marie-Christine Rybarczyk-Vigouret ${ }^{2}$. \\ José Covassin $^{3} \cdot$ Christelle Sordet $^{4} \cdot$ Bruno Michel $^{2,5}$
}

Published online: 16 July 2015

(C) The Author(s) 2015. This article is published with open access at Springerlink.com

\begin{abstract}
Background The economic burden linked to rheumatoid arthritis (RA) has greatly increased since the inclusion of biotherapies in the therapeutic arsenal.

Objectives This study aimed first to look at the breakdown of the rheumatoid arthritis patients on biotherapy in Alsace, France, in 2012, then to evaluate the annual cost per treated patient for each management pathway: inpatient care with intravenous biotherapies and/or outpatient care through the use of subcutaneous drugs, and finally to conduct a cost comparison with a focus on infliximab, adalimumab and etanercept.

Methods This observational study was conducted in Alsace using 2012 health claims data from the DCIR (Données de Consommation Inter Régime) and PMSI (Programme de Médicalisation des Systèmes d'Information) databases, taking into account direct medical and non-medical costs in a real-life setting and from a National Health Insurance perspective.

Results There were 5702 RA patients, i.e. $0.31 \%$ of the Alsace population in 2012, including 1075 subjects

Morgane Beck

morganebeck68@gmail.com; Morgane.BECK@ars.sante.fr

1 Laboratoire d'épidémiologie et de santé publique-EA 3430, Faculté de Médecine, Université de Strasbourg, 67085 Strasbourg Cedex, France

2 OMEDIT Alsace, Agence Régionale de Santé d'Alsace, 14, rue du Maréchal Juin, 67084 Strasbourg Cedex, France

3 Direction Régionale du Service Médical d'Alsace-Moselle, 67003 Strasbourg Cedex, France

4 Service de rhumatologie, Hôpital de Hautepierre, Hôpitaux Universitaires de Strasbourg, 67098 Strasbourg Cedex, France

5 Service de Pharmacie, Nouvel Hôpital Civil, Hôpitaux Universitaires de Strasbourg, Laboratoire HuManiS-EA 7308, Faculté de Pharmacie, Université de Strasbourg, 67098 Strasbourg Cedex, France
\end{abstract}

(18.85\%) receiving biotherapy treatment. The most frequently prescribed biotherapies were etanercept and adalimumab. The estimated overall cost of care of these 5702 patients was $€ 30.3$ million, with about $50 \%$ for the care of the $18.85 \%$ patients on biotherapy. Average costs for inpatient, outpatient and mixed care ranged from $€ 14,197$ to $€ 16,873$ per patient per year. Annual average cost for management of a single RA patient with infliximab was significantly higher than with adalimumab and etanercept: $€ 16,480$ versus $€ 14,116$ and $€ 14,338$, respectively.

Conclusion These findings confirm the trends of initial modelling approaches and quantify the cost difference between various biotherapy management pathways.

\section{Key Points}

The study included rheumatoid arthritis (RA) patients treated with any of the nine biotherapies available in 2012 in France, and evaluated the annual cost per patient through a data linkage between inpatient and outpatient care for the same individual.

Outpatient care was the main management pathway observed. Etanercept and adalimumab were the most commonly used biotherapies to treat RA patients.

Biotherapy acquisition costs and hospital stays were the two main areas of expenditure.

Annual average cost per RA patient management with infliximab was significantly higher compared to patients treated with adalimumab or etanercept. The highest cost of infliximab was essentially explained by the additional hospitalization cost associated with hospital facilities, transportation and higher number of laboratory tests. 


\section{Introduction}

The last decade saw the transition for the treatment of moderate-to-severe rheumatoid arthritis (RA) from general immunomodulators to biotherapies. Recent therapeutic guidelines have positioned the biotherapies in the therapeutic arsenal [1-5]. Early treatment of RA with biotherapies translates into substantial cost savings as they appear to improve work ability or prevent future orthopaedic surgery. However, these biological drugs are associated with high procurement costs [6-8].

In parallel, sweeping changes in the organisation of the French healthcare policy have occurred with the implementation since 2004 of a Diagnosis-Related-Groups (DRG) based payment system correlating the government funding of each hospital with specific activity parameters. In addition to the above, innovative and expensive drugs like biotherapies are included in a restricted list: they are completely funded in addition to hospitalisation stays. This payment scheme enables all hospitals to have access to these therapies. However, the percentage of range of cost increase for these innovative drugs is pre-defined at a national level, in an attempt to control the cost expenditure [9].

In this context of close health cost control, a better understanding of how biotherapies impact the costs of managing RA will allow improvement in decisions concerning resource allocation, and also reinforce the compliance with therapeutic guidelines. Predicting the annual cost of biotherapies is complex due the differences in dosing schedules. Furthermore, patients may not respond and may require dose escalation over time or a switch between biotherapies. Some biotherapies are only administered at the hospital while others can also be administered by subcutaneous (SC) route at home, leading to different management pathways [10]. SC biotherapies affect outpatient care expenditure, while intravenous (IV) biotherapies have an impact on hospital expenses. Those differences can lead to a potential reduction of hospital activity which in turn needs to be anticipated.

This study aimed first to look at the breakdown of the RA patients on biotherapy in 2012 in Alsace, and second to estimate the annual cost per treated patient for each management pathway: inpatient care with IV medications and/or outpatient care through the use of SC drugs, all in a real-life setting, and finally to complete a cost comparison with a focus on infliximab, adalimumab and etanercept.

\section{Patients and Methods}

\subsection{Data Source}

A retrospective observational study was conducted by OMEDIT Alsace (Observatoire du Médicament, des Dispositifs médicaux et de l'Innovation Thérapeutique) using administrative claims data from the DCIR (Données de Consommation Inter Régime) and PMSI (Programme de Médicalisation des Systèmes d'Information) databases from 1 January 2012 to 31 December 2012. Alsace is a French administrative region that accounted for 1.86 million inhabitants in 2012 at whatever age, i.e. $3 \%$ of the French population, and among them 1.41 million people aged 20 years or over.

Data relative to outpatient care and to inpatient care are stored and linked into the DCIR datamart that is part of the SNIIRAM (Système National d'Information Interrégimes de l'Assurance Maladie) data warehouse of National Health Insurance, that records anonymised data about patients who benefit from medical care with intent of having adequate knowledge on expenses concerning all health insurance schemes, thus enabling evaluation of public health policy. The main benefit of its use for epidemiological purposes is to have access to information about the healthcare circuit including hospitalisation and outpatient care for the same individual. Its access is restricted to authorised people specified through a national policy. Information strictly required for the purpose of the study was provided in the form of anonymised and aggregated data by DRSM (Direction Régionale du Service Médical) Alsace-Moselle that has access to DCIR and PMSI databases with respect to the approval of the French data protection authority CNIL (Commission nationale de l'informatique et des libertés). Data extracted concerned the patient population residing and insured in Alsace under the general scheme managed by CNAMTS (Caisse Nationale de l'Assurance Maladie des Travailleurs Salariés), which covered $80 \%$ of residents in Alsace in 2011 [11].

\subsection{Rheumatoid Arthritis Patient Population}

RA is one of the chronic diseases included in the Long Term Diseases (LTD) list for which CNAMTS provides $100 \%$ health insurance coverage. Data extracted from the DCIR and PMSI databases enabled us to consider all RA patients in a real-life setting. The RA patients included in the study were defined as patients residing and insured in Alsace under the general scheme managed by CNAMTS, 
who were at least 20 years or older and who had RA classified as LTD no. 22, irrespective of whether or not they had another disease classified as another LTD with the exception of LTD no. 24 (ulcerative colitis and Crohn's disease) and LTD no. 27 (severe active ankylosing spondylitis), since some biotherapies are also approved for use in patients with one or both of these latter diseases [10]. Data pertaining to hospitalisation were described with the possible attribution of one of the following diagnostic codes as the principal or related diagnosis as per the ICD10 (International Classification of Diseases-10th revision), namely code M05: seropositive rheumatoid arthritis and code M06: other rheumatoid arthritis. The main point for defining a RA population was of having LTD no. 22 with or without hospitalisation with RA codes encoded as primary or secondary diagnosis.

\subsection{Biotherapies}

Several biotherapies were indicated for the treatment of RA in France in 2012 (see Table 1): infliximab, abatacept, tocilizumab and rituximab, which were administered by infusion at hospital, and adalimumab, etanercept, golimumab, certolizumab and anakinra, which were administered by SC route at home [10]. RA patients were included in the biotherapy group as they had at least one claim for a biotherapy treatment registered in the DCIR in 2012. Three biotherapy management pathways have been distinguished: inpatient care that corresponds to patients who are systematically administered biotherapy treatment by infusion at hospital, whether or not they switch from an IV biotherapy to another IV biotherapy during the year of the study; outpatient care that groups patients who are systematically administered biotherapy treatment by the SC route at home, whether or not they switch from a SC biotherapy to another SC biotherapy during the study period; and finally mixed care that clusters patients who switch from IV biotherapy to SC biotherapy or vice versa.

\subsection{Costs}

The viewpoint of the study was that of the French National Health Insurance CNAMTS.

The following direct medical and non-medical cost categories were taken into account for each patient, whether or not he was on biotherapy, and rounded up to the nearest 10 euros: costs for treatment include cost of biotherapy and concomitant medications, and management costs including inpatient and outpatient care. Inpatient care costs were determined on the basis of the 2012 French tariffs per DRG relative to hospitalization in medical, surgical and obstetric wards. Cost data regarding outpatient care were relative to consultation with a general practitioner or a specialist, cost of SC injections administered at home by nurses were included as well. Other costs included expenses incurred for performing laboratory tests, radiology examinations and kinesitherapy on the patient. A last cost category related to transport expenses. Since all patients included in the study had a RA classified as LTD no. 22 , all costs were fully covered by the French National Health Insurance CNAMTS, so that the total expenditure was taken into account.

\subsection{Statistical Analysis}

A first descriptive analysis was carried out in order to describe the biotherapy distribution in the entire RA population, and to calculate the overall cost to support the RA patient care. Then, patients considered to be treated for less than 8 months with biotherapies in 2012 were dropped from the study in order to get a more realistic value of the actual annual average cost per RA patient management. Otherwise, this would have led to an under-estimation of its value. Comparison of demographic variables and clinical characteristics were performed using the Chi-square test, since all of the variables were categorical variables. Annual average costs per patient stratified by biotherapy and concerning infliximab, adalimumab and etanercept were compared using the Mann-Whitney $U$ test. A sensitivity analysis was carried out in order to check if costs of managing RA with biotherapies were robust to changes in biotherapy treatment duration, if patients were treated for more than 6,8 or 10 months.

A $p$ value below 0.05 was considered to be of statistical significance. Computations were performed using $\mathrm{R}$, version 3.1.0.

\section{Results}

\subsection{Biotherapy Distribution in the Patient Population}

There were 5702 RA patients, i.e. $0.31 \%$ of overall population of Alsace in 2012, of whom 1075 (18.85\% of RA patients) were under biotherapy treatment. Outpatient care represented $63.8 \%$ of situations studied whereas inpatient care and mixed care reached 32.5 and $3.7 \%$, respectively, of the overall health care for RA. Each of the three subgroups was divided into different treatment groups, according to the modalities that are described in Table 2 . Infliximab, adalimumab and etanercept treatment without any switch during the year represented about two-thirds $(66.1 \%)$ of the different management pathways observed. The most commonly used biotherapies were etanercept and adalimumab, which were used for 368 patients (31.4\%) and 339 patients $(28.9 \%)$, respectively, whether or not 
Table 1 Biotherapies available in France in 2012 for treating rheumatoid arthritis

\begin{tabular}{|c|c|c|c|}
\hline Biotherapy & $\begin{array}{l}\text { Packaging, } \\
\text { presentation }\end{array}$ & $\begin{array}{l}\text { Biotherapy } \\
\text { management }\end{array}$ & Dosage as per SPC, dosing frequency \\
\hline $\begin{array}{l}\text { Infliximab } \\
\quad\left(\text { Remicade }^{\circledR}\right)\end{array}$ & $\begin{array}{l}100 \mathrm{mg} \\
1 \text { vial }\end{array}$ & Inpatient care & $3 \mathrm{mg} / \mathrm{kg}$ per injection (up to $7.5 \mathrm{mg} / \mathrm{kg}$ ) W0, W2, W6 then every 8 weeks \\
\hline $\begin{array}{c}\text { Adalimumab } \\
\left(\text { Humira }^{\circledR}\right)\end{array}$ & $\begin{array}{l}40 \mathrm{mg} \\
2 \text { syringes or pens }\end{array}$ & Outpatient care & $40 \mathrm{mg}$ per injection every 2 weeks (up to weekly) \\
\hline $\begin{array}{l}\text { Etanercept } \\
\left(\text { Enbrel }^{\circledR}\right)\end{array}$ & $\begin{array}{l}25 \mathrm{mg}, 50 \mathrm{mg} \\
4 \text { syringes } \\
50 \mathrm{mg} \\
4 \text { pens }\end{array}$ & Outpatient care & $25 \mathrm{mg}$ per injection twice a week, or $50 \mathrm{mg}$ per injection once weekly \\
\hline $\begin{array}{l}\text { Abatacept } \\
\quad\left(\text { Orencia }^{\circledR}\right)\end{array}$ & $\begin{array}{l}250 \mathrm{mg} \\
1 \text { vial }\end{array}$ & Inpatient care & $\begin{array}{l}<60 \mathrm{~kg}: 500 \mathrm{mg} \text { per injection } \mathrm{W} 0, \mathrm{~W} 2, \mathrm{~W} 4 \text { then monthly; } 60 \mathrm{~kg} \text { up to } 100 \mathrm{~kg} \text { : } \\
750 \mathrm{mg} \text { per injection } \\
\mathrm{W} 0, \mathrm{~W} 2, \mathrm{~W} 4 \text { then monthly; }>100 \mathrm{~kg}: 1000 \mathrm{mg} \text { per injection } \mathrm{W} 0, \mathrm{~W} 2, \mathrm{~W} 4 \text { then } \\
\text { monthly }\end{array}$ \\
\hline $\begin{array}{l}\text { Tocilizumab } \\
\left(\text { Roactemra }^{\circledR}\right)\end{array}$ & $\begin{array}{l}80 \mathrm{mg}, 200 \mathrm{mg}, \\
\quad 400 \mathrm{mg} \\
1 \text { vial }\end{array}$ & Inpatient care & $8 \mathrm{mg} / \mathrm{kg}$ per injection monthly \\
\hline $\begin{array}{l}\text { Rituximab } \\
\quad\left(\text { Mabthera }^{\circledR}\right)\end{array}$ & $\begin{array}{l}100 \mathrm{mg} \\
2 \text { vials } \\
500 \mathrm{mg} \\
1 \text { vial }\end{array}$ & Inpatient care & $1000 \mathrm{mg}$ per injection $\mathrm{W} 0$ and $\mathrm{W} 2$ and re-evaluation after 24 weeks \\
\hline $\begin{array}{l}\text { Golimumab } \\
\left(\text { Simponi }^{\circledR}\right)\end{array}$ & $\begin{array}{l}50 \mathrm{mg} \\
1 \text { syringe or pen }\end{array}$ & Outpatient care & $50 \mathrm{mg}$ (up to $100 \mathrm{mg}$ if patient $>100 \mathrm{~kg}$ ) per injection monthly \\
\hline $\begin{array}{l}\text { Certolizumab } \\
\left(\text { Cimzia }^{\circledR}\right)\end{array}$ & $\begin{array}{l}200 \mathrm{mg} \\
2 \text { vials }\end{array}$ & Outpatient care & $\begin{array}{l}400 \mathrm{mg} \text { per injection W0, W2, W4 then } 200 \mathrm{mg} \text { per injection every } 2 \text { weeks or } \\
400 \mathrm{mg} \text { per injection monthly }\end{array}$ \\
\hline $\begin{array}{l}\text { Anakinra } \\
\left(\text { Kineret }^{\circledR}\right)\end{array}$ & $\begin{array}{l}100 \mathrm{mg} \\
7 \text { syringes }\end{array}$ & Outpatient care & $100 \mathrm{mg}$ per injection daily \\
\hline
\end{tabular}

$S P C$ summary of product characteristics, $W$ week

they switched to another biotherapy. This was followed by IV biotherapies: abatacept which was used to treat 59 patients $(5.0 \%)$, tocilizumab and rituximab were used to treat a total of 201 patients $(17.2 \%)$, and infliximab was used to treat 137 patients $(11.7 \%)$. Overall, 844 patients $(72.0 \%)$ were prescribed infliximab and/or adalimumab and/or etanercept. Other SC biotherapies listed here were among the least represented with only 69 patients thus treated $(5.9 \%)$ in 2012: 51 with certolizumab, ten with anakinra and eight with golimumab. The main mixed care switch was between adalimumab and IV biotherapy (11 patients, i.e. $27.5 \%$ ). The second situation experienced was a switch between etanercept and IV biotherapy (nine patients, i.e. $22.5 \%$ ). Over the total mixed care switch situations encountered, 35 situations $(87.5 \%)$ involved at least one anti-TNF treatment.

\subsection{Description of Cost Categories}

Overall cost to support the 5702 RA patient care in Alsace in 2012 was $€ 30.3$ million, and costs related to the $18.85 \%$ of RA patients on biotherapy accounted for $€ 14.9$ million, representing $49.2 \%$ of this total amount. Biotherapy acquisition cost represented the largest part of the cost attributable to RA treatment containing biotherapies, followed by hospitalisation cost. In fact, about $€ 10$ million could be attributed to the procurement of the biological drugs and $€ 2.4$ million linked to hospital facilities, i.e. 67.5 and $16.2 \%$ of the overall expenditure regarding RA patients treated with biotherapies. Almost a quarter of total cost allocated to the management of RA patients that were not treated with biotherapies was attributed to visits to physicians. Details are provided in Table 3.

\subsection{Baseline Clinical and Demographic Characteristics}

After excluding the 213 patients treated for less than 8 months with biotherapies in 2012, a total of 862 patients under biotherapy remained for the analysis. A patient selection flowchart is provided in Fig. 1. In the remaining RA population $(n=5489)$, the male/female sex ratio was 
Table 2 Biotherapy management pathways of adult rheumatoid arthritis patients in Alsace in 2012

\begin{tabular}{|c|c|c|}
\hline Biotherapy management pathways & Number of patients & $\%$ \\
\hline Inpatient care & 349 & 32.5 \\
\hline Infliximab without any switch & 117 & 10.9 \\
\hline IV biotherapy (other than infliximab) with or without any switch & 224 & 20.8 \\
\hline Switch infliximab and IV biotherapy (other than infliximab) & 8 & 0.7 \\
\hline Outpatient care & 686 & 63.8 \\
\hline Adalimumab without any switch & 284 & 26.4 \\
\hline Etanercept without any switch & 310 & 28.8 \\
\hline Switch adalimumab and etanercept & 31 & 2.9 \\
\hline Switch adalimumab and SC biotherapy (other than adalimumab and etanercept) & 7 & 0.7 \\
\hline Switch etanercept and SC biotherapy (other than adalimumab and etanercept) & 8 & 0.7 \\
\hline SC biotherapy (other than adalimumab and etanercept) with or without any switch & 46 & 4.3 \\
\hline Mixed care & 40 & 3.7 \\
\hline Switch SC biotherapy and IV biotherapy & 40 & 3.7 \\
\hline Total & 1075 & 100.0 \\
\hline
\end{tabular}

$S C$ subcutaneous, SC biotherapy golimumab, certolizumab, anakinra, $I V$ intravenous, $I V$ biotherapy abatacept, tocilizumab, rituximab

Table 3 Breakdown of costs to support the care of rheumatoid arthritis patients in Alsace in 2012

\begin{tabular}{|c|c|c|c|c|c|}
\hline \multirow[t]{2}{*}{ Cost domain } & \multicolumn{2}{|c|}{ Total costs (euros) } & \multicolumn{3}{|l|}{ Biotherapy } \\
\hline & $\begin{array}{l}\text { All patients } \\
(n=5702)\end{array}$ & $\begin{array}{l}\text { Without biotherapy } \\
(n=4627)\end{array}$ & $\begin{array}{l}\text { Inpatient care } \\
(n=349)\end{array}$ & $\begin{array}{l}\text { Outpatient care } \\
(n=686)\end{array}$ & $\begin{array}{l}\text { Mixed care } \\
(n=40)\end{array}$ \\
\hline Biotherapy & $10,068,780$ & 0 & $3,131,030$ & $6,498,810$ & 438,940 \\
\hline Visits to physicians & $4,807,180$ & $3,828,230$ & 318,080 & 621,670 & 39,200 \\
\hline Nurse visits & $1,425,350$ & $1,259,780$ & 66,930 & 89,310 & 9330 \\
\hline Kinesitherapy & $1,160,790$ & 951,370 & 79,010 & 123,770 & 6640 \\
\hline Transportation & $1,127,200$ & 769,920 & 213,170 & 127,990 & 16,120 \\
\hline Laboratory tests & $1,760,340$ & $1,293,160$ & 203,220 & 241,420 & 22,540 \\
\hline Radiology & $1,167,390$ & 910,010 & 87,480 & 159,770 & 10,130 \\
\hline Hospital facilities & $8,799,530$ & $6,389,000$ & $1,480,000$ & 809,180 & 121,350 \\
\hline Total cost & $30,316,560$ & $15,401,470$ & $5,578,920$ & $8,671,920$ & 664,250 \\
\hline
\end{tabular}

0.38 ( $n=1516$ vs. 3973$)$ and the median age range was 60-69 years. Patients on biotherapy were younger, had fewer comorbidities recognised as LTD and consulted a general practitioner or a specialist more frequently. Baseline characteristics of the study population are summarised in Table 4.

\subsection{Comparison of Annual Average Costs per Patient}

Annual average costs relative to inpatient, outpatient and mixed care are given in Table 5. When looking at patients treated for at least 8 months with biotherapy, biotherapy acquisition costs and hospital stays were the two major items of expenditure, representing $83.4 \%$ of the total expenses of inpatient care, and $84.4 \%$ of total expenses of mixed care. The amount allocated to biotherapy acquisition reached in itself $80.7 \%$ of the total outpatient care expenses.

Table 6 shows annual average costs per patient with a focus on the three anti-tumour necrosis factor alpha (antiTNF $\alpha$ ) therapies infliximab, adalimumab and etanercept, without any switch during the study period. There were no significant cost differences between adalimumab and etanercept, with the exception of biotherapy acquisition, which was greater for adalimumab, and for nurse visits and laboratory tests, which were greater for etanercept. When comparing infliximab with adalimumab and with etanercept, there were no cost differences relative to visits to physicians, nurse visits, kinesitherapy and radiology. Costs relative to biotherapy acquisition were higher for adalimumab and etanercept, and those relative to transport, 


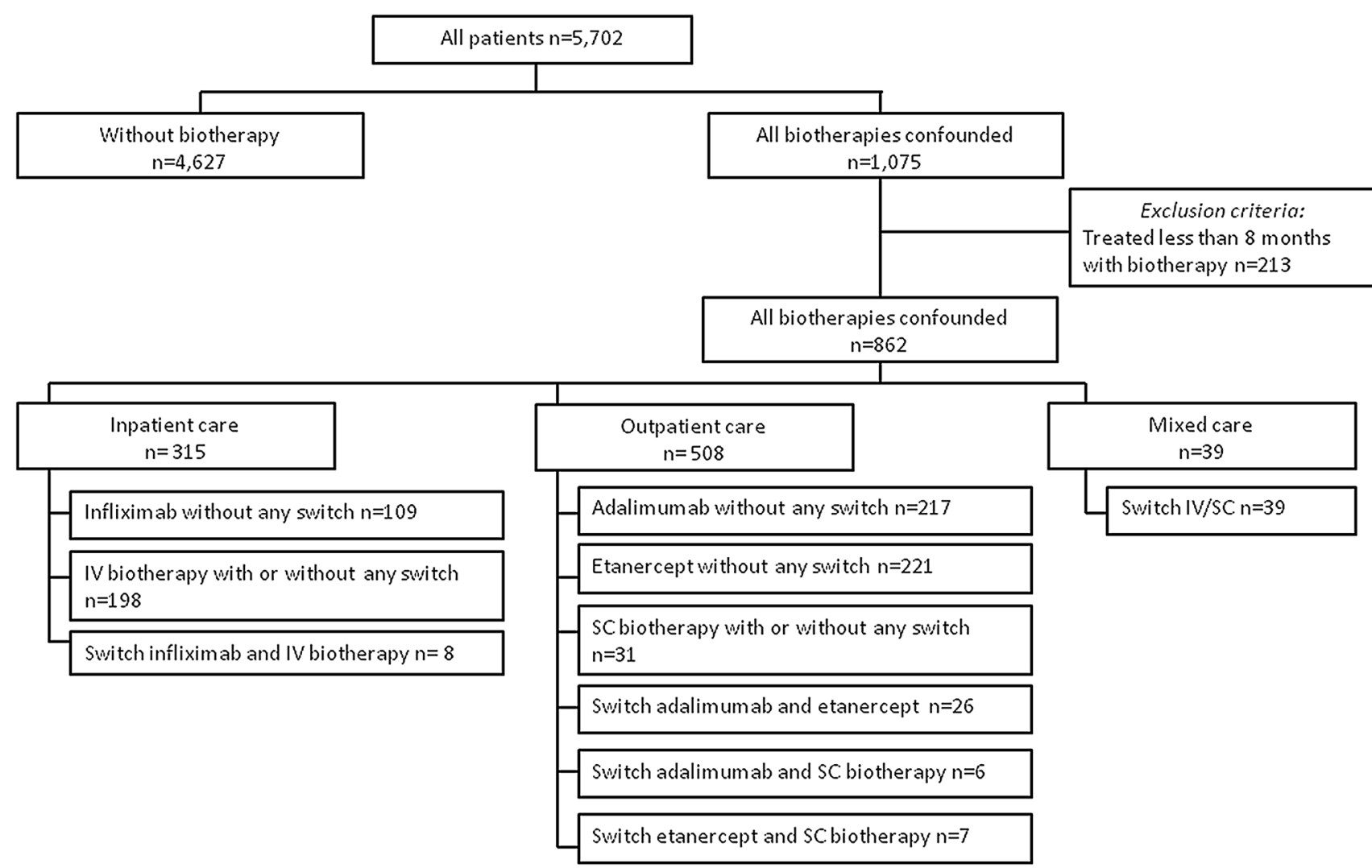

Fig. 1 Patient selection flowchart of adult rheumatoid arthritis patients in Alsace in 2012. SC subcutaneous, SC biotherapy golimumab, certolizumab, anakinra, $I V$ intravenous, $I V$ biotherapy abatacept, tocilizumab, rituximab

Table 4 Clinical and demographic characteristics of adult rheumatoid arthritis patients in Alsace in 2012

\begin{tabular}{|c|c|c|c|c|c|}
\hline $\begin{array}{l}\text { Characteristics } \\
(n, \%)\end{array}$ & $\begin{array}{l}\text { All RA } \\
\text { patients } \\
(n=5489)\end{array}$ & $\begin{array}{l}\text { Without } \\
\text { biotherapy } \\
(n=4627)\end{array}$ & $\begin{array}{l}\text { All biotherapies combined } \\
\text { (overall biotherapy population) } \\
(n=1075)\end{array}$ & $\begin{array}{l}\text { All biotherapies combined } \\
\text { and treated }<8 \text { months } \\
(n=213)\end{array}$ & $\begin{array}{l}\text { All biotherapies combined } \\
\text { and treated }>8 \text { months } \\
(n=862)\end{array}$ \\
\hline \multicolumn{6}{|l|}{ Age range, years } \\
\hline $20-29$ & 104 (1.9) & $76(1.6)$ & $40(3.7)$ & $12(5.6)$ & $28(3.2)$ \\
\hline $30-39$ & $274(5.0)$ & $203(4.4)$ & $96(8.9)$ & $25(11.7)$ & $71(8.2)$ \\
\hline $40-49$ & $602(11.0)$ & $448(9.7)$ & $204(19.0)$ & $50(23.5)$ & 154 (17.9) \\
\hline $50-59$ & 1075 (19.6) & $796(17.2)$ & $325(30.2)$ & $46(21.6)$ & $279(32.4)$ \\
\hline $60-69$ & 1243 (22.6) & $1037(22.4)$ & $255(23.7)$ & $49(23.0)$ & $206(23.9)$ \\
\hline $70-79$ & $1132(20.6)$ & $1033(22.3)$ & 125 (11.6) & $26(12.2)$ & 99 (11.5) \\
\hline$\geq 80$ & $1059(19.3)$ & $1034(22.3)$ & $30(2.8)$ & $5(2.3)$ & $25(2.9)$ \\
\hline Gender: male & $1516(27.6)$ & $1260(27.2)$ & $332(30.9)$ & $76(35.7)$ & $256(29.7)$ \\
\hline $\begin{array}{l}\text { Other LTD in } \\
\text { addition to LTD } \\
\text { no. } 22\end{array}$ & $2266(41.3)$ & $2032(43.9)$ & $286(26.6)$ & $52(24.4)$ & $234(27.1)$ \\
\hline $\begin{array}{l}\text { Consultation with } \\
\text { a general } \\
\text { practitioner }\end{array}$ & $4411(80.4)$ & $3618(78.2)$ & $992(92.3)$ & 199 (93.4) & $793(92.0)$ \\
\hline $\begin{array}{l}\text { Consultation with } \\
\text { a specialist }\end{array}$ & 2133 (38.9) & $1668(36.0)$ & $602(56.0)$ & $137(64.3)$ & $465(53.9)$ \\
\hline
\end{tabular}

LTD long-term disease 


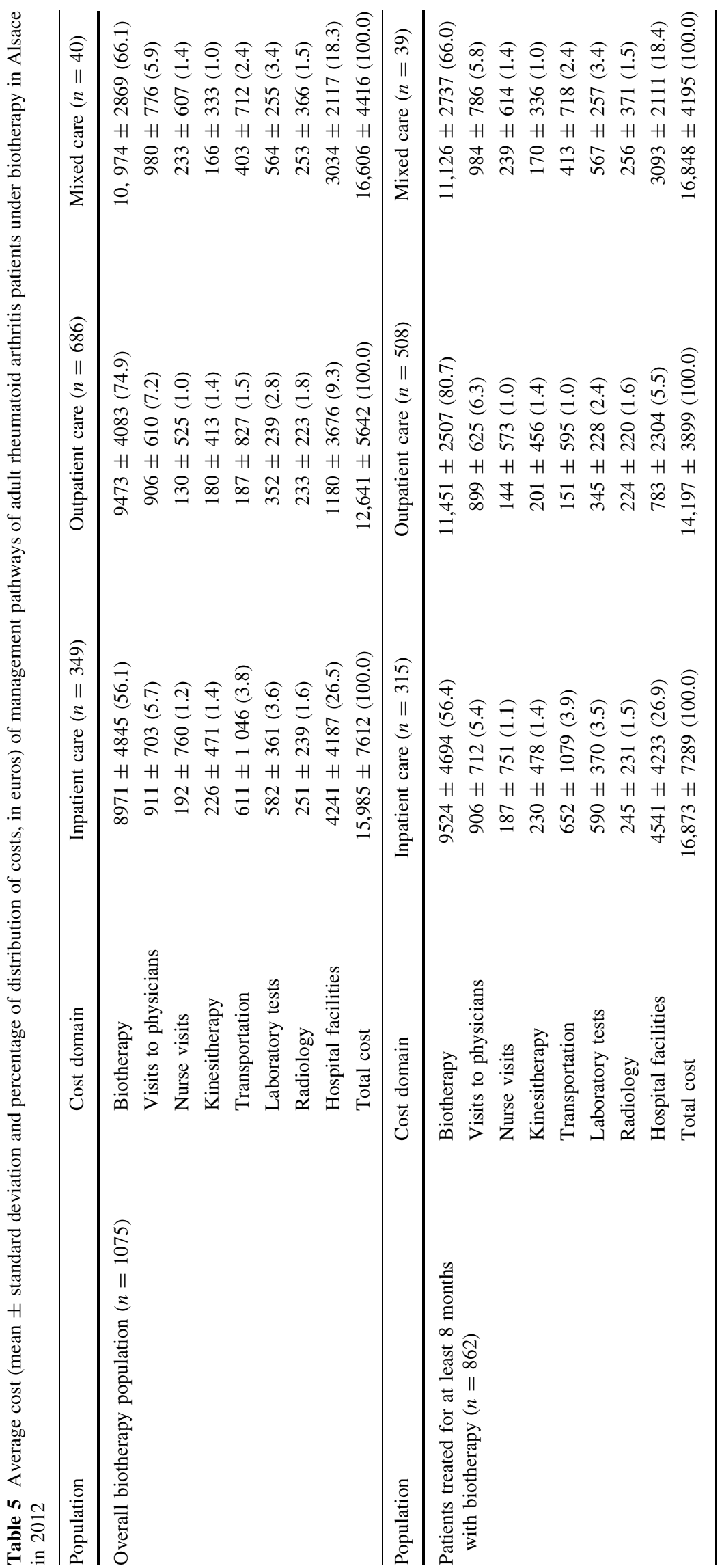


laboratory tests and hospitalisation were greater for infliximab. Annual average cost per RA patient management with infliximab was significantly higher than those with adalimumab and etanercept: $€ 16,480$ vs. $€ 14,116$ and $€ 14,338$, respectively. The higher cost of infliximab was mainly explained by additional hospitalisation costs linked to hospital facilities, transportation and more frequent laboratory tests. A sensitivity analysis was carried out and showed the costs of managing RA with biotherapies were robust to changes in biotherapy treatment duration, so that the average cost per RA patient management with infliximab was lower than that with adalimumab and etanercept, whether they were treated for more than 6,8 or 10 months.

\section{Discussion}

Previous pharmacoeconomic assessments compared costs for administering biotherapies for treating inflammatory rheumatic diseases at both the national and international levels [12-19]. French analyses were theoretical approaches and/or took into consideration only the data extracted from hospital databases (PMSI) [12, 13]. This appears to be the first French study describing inpatient and outpatient costs of biotherapy management pathways in RA using data collected from the National Health Insurance claims database. The study indicates that $18.85 \%$ of RA patients were treated with biotherapies in Alsace in 2012, which represented $€ 14.9$ million of the total expenses, and this accounts for almost half of the total amount allocated to treat all RA patients.

There were 5702 patients with RA classified as a LTD no. 22, corresponding to $0.31 \%$ of the inhabitants in Alsace in 2012 when using the number of people whatever their age, i.e. 1.86 million inhabitants. We chose to calculate the percentage of RA patients using the number of people whatever their age, since the number of RA patients under 20 years old was considered to be negligible, as it represented $1.5 \%$ of entire population with RA classified as LTD no. 22 . When only considering the number of 1.41 million of people aged 20 years or over in Alsace in 2012, the proportion of RA patients for this age group increased to $0.40 \%$. Although this result cannot be treated as prevalence per se, it is consistent with data from the French EPIRHUM2 (Epidémiologie des rhumatismes inflammatoires) survey that showed in 2001 a RA prevalence of $0.31 \%$ in France, as well as in Lorraine, which is a border region of Alsace [20, 21]. Another study conducted in the northern part of France indicated a prevalence of RA of about $0.20 \%$ in 2005 [22]. Demographic results are coherent with previous studies such as the EPIRHUM-2 survey that showed there was a higher age-specific prevalence of RA in the 65-74 years age range, and a 2004 study that described the characteristics of RA patients managed by hospital-based rheumatologists in France and showed a male/female sex ratio of 0.29 and a mean age of 56.7 years [23].

When ranking the number of patients under biotherapies, the main management pathway encountered was that of outpatient care $(63.8 \%)$, and more than $60 \%$ of patients were treated with etanercept or adalimumab. This result supports previous findings of national and international studies showing that outpatient care is an option used extensively in everyday practice [12-17]. The lower use of golimumab, certolizumab and abatacept in 2012 can be explained by the fact that they were commercialised later (September 2012, April 2010 and December 2011, respectively). Few changes in the administration route of the biotherapy treatment were observed during the year in our study: less than $4.0 \%$ of mixed care that could correspond to intolerance or to non-responders, due to the emergence of resistance or to a poor adherence to treatment.

Table 6 Average cost (mean \pm standard deviation, in euros) of adult rheumatoid arthritis patients treated for at least 8 months with infliximab (INF), adalimumab (ADA) or etanercept (ETA), without any switch, in Alsace in 2012

\begin{tabular}{lcccccc}
\hline Cost domain & INF $(n=109)$ & ADA $(n=217)$ & ETA $(n=221)$ & $p$ value INF/ADA ${ }^{\text {a }}$ & $p$ value INF/ETA & $p$ value ADA/ETA \\
\hline Biotherapy & $10,345 \pm 5125$ & $11,630 \pm 2356$ & $11,437 \pm 2669$ & $<0.01^{*}$ & $<0.01^{*}$ & $0.01^{*}$ \\
Visits to physicians & $898 \pm 691$ & $832 \pm 571$ & $893 \pm 619$ & 0.23 & 0.54 & 0.40 \\
Nurse visits & $87 \pm 305$ & $138 \pm 577$ & $161 \pm 641$ & 0.45 & 0.20 & $0.04^{*}$ \\
Kinesitherapy & $151 \pm 355$ & $189 \pm 436$ & $213 \pm 466$ & 0.91 & 0.63 & 0.64 \\
Transportation & $493 \pm 862$ & $111 \pm 421$ & $133 \pm 437$ & $<0.01^{*}$ & $<0.01^{*}$ & 0.59 \\
Laboratory tests & $499 \pm 316$ & $311 \pm 206$ & $351 \pm 227$ & $<0.01^{*}$ & $<0.01^{*}$ & $0.03^{*}$ \\
Radiology & $219 \pm 183$ & $209 \pm 211$ & $212 \pm 206$ & 0.87 & 0.61 & 0.44 \\
Hospital facilities & $3788 \pm 3270$ & $696 \pm 2124$ & $938 \pm 2658$ & $<0.01^{*}$ & $<0.01^{*}$ & 0.29 \\
Total cost & $16,480 \pm 6677$ & $14,116 \pm 3736$ & $14,338 \pm 4187$ & $<0.01^{*}$ & $<0.01^{*}$ & 0.56 \\
\hline
\end{tabular}

* Statistically significant, Mann-Whitney $U$ test

${ }^{\text {a }}$ Comparison between INF and ADA after matching based on age groups $(n=109)$ 
The study showed that the average cost of adult RA patients treated with IV biotherapies seemed to be higher than that of outpatient care, and that the average cost for patients treated with infliximab was significantly higher than that with adalimumab and etanercept. This finding was quite surprising since the biological follow-up is supposed to be the same whatever the type of biologic used. We assumed that patients under treatment with infliximab may have a systematic biological follow-up when they go to hospital, and are followed more closely than patients under SC biotherapies. Moreover, recommendations for monitoring RA patients treated with anti-TNF $\alpha$ are: one biological follow-up (liver function tests and complete blood count) at 1 and 3 months, then every 3 months for SC biotherapies, and a biological follow-up at each perfusion, such as every month for infliximab. The monitoring frequency difference could account for why laboratory tests are more costly in the infliximab group.

Cost comparison is only valuable when efficacy and safety of drugs are comparable. Previous studies demonstrated that biotherapies were effective treatments compared to placebo or conventional drugs, and a 2010 metaanalysis showed there were no significant differences in efficacy at 24 weeks between etanercept, adalimumab and infliximab with or without methotrexate treatment $[24,25]$. A 2014 review indicated there was no difference in efficacy or in the side-effect profiles between IV and SC biotherapies [26]. Moreover, marketing authorisation for use in RA was granted for a sufficient period of time so that infliximab, adalimumab and etanercept benefited from a particularly extensive post-marketing experience, making the comparison between those three anti-TNF $\alpha$ therapies available [10]. Cost comparison demonstrated RA patient management was less costly with adalimumab or etanercept than with infliximab. The main cost difference between the three biotherapy options was the hospitalisation cost, which was significantly greater for the IV medication than for SC drugs. When comparing these results with those of international studies evaluating costs in the setting of real world data, it is now obvious that treatment with infliximab is the most expensive. In fact, Schabert et al. [14] carried out a study looking at the annual cost per patient from the payer perspective for etanercept, adalimumab and infliximab in adults with rheumatoid arthritis, psoriasis, psoriatic arthritis or ankylosing spondylitis [14]. They showed that the annual cost per treated RA patient was lowest for etanercept, followed by adalimumab and infliximab (US $\$ 16,787$ vs. US $\$ 19,308$ and US $\$ 22,939$, respectively). The main difference from our study is the identification of a cost difference between adalimumab and etanercept. However, this study did not conduct a direct comparison of these costs and took only the costs of acquisition and administration of biotherapies into account.
A retrospective USA claims analysis providing an evaluation of drug utilisation and costs in a population of RA patients treated with one of the three anti-TNF $\alpha$ treatments conducted by Bonafede et al. [16] led to the same conclusions than the study of Schabert et al. [14], with an annual cost per treated patient of US $\$ 18,466$ for etanercept, US\$20,983 with adalimumab and US\$26,516 with infliximab. Here again, the main differences compared to our study are the following: a direct statistical comparison of costs was not planned nor conducted, and the study only considered direct costs as acquisition and administration of biotherapies. In another survey, Zeidler et al. [19] studied real-life data on costs and dosing patterns in the utilisation of adalimumab, etanercept and infliximab in patients treated in Switzerland for inflammatory rheumatic diseases. Their conclusions were the same as ours when considering daily costs of treatment. They showed that medication costs were by far the most important cost driver, and that daily costs of treatment were similar for etanercept and adalimumab, but were higher for infliximab. One of the main assets of this study was a more complete analysis of direct costs, including, for example, laboratory tests. This analysis, however, was conducted on the entire population suffering from inflammatory rheumatic diseases without any differentiation between RA, ankylosing spondylitis and psoriatic arthritis.

The current study describes direct medical and non-medical costs taking all biotherapies into account and in a real-life setting. Aside from the possible criticism that quality of medico-administrative databases is more debatable than that of registries devoted to epidemiological surveillance, it is important to recognise that their quality improvement in terms of content and encoding is a constant concern for both CNAMTS and supervisory authorities [27]. The primary goal of medico-administrative databases is to provide information about management and payment of medical care, but their usefulness to support epidemiological studies is now well recognised thanks to their frequent updating and comprehensiveness that allows their use for recent years at more finetuned geographical levels. These tools are an asset for studies related to healthcare issues and to the optimisation of the resources management. Moreover, due to their compulsory fulfilling, few data are missing from those databases in contrast to some studies that require data collection in a declaratory mode [28]. It is also important to note that the price of the medicines remained stable over the entire year of the study.

The study had some limitations. Firstly, patients who were not insured under the general scheme were not taken into account. Secondly, data about indirect and intangible costs are lacking because of their relative complexity. Therefore, cost of illness is underestimated but cost comparison should not have been affected since indirect and intangible costs are considered to be the same in each 
group. Thirdly, it may be noted that the study provided a snapshot of biotherapies used at a given point in time and did not allow for the observation of changes in prescribing practices over a longer period. Finally, existence of confounding by indication cannot be ruled out. That bias largely met in observational studies would reflect the fact that IV biotherapies could be prescribed in preference to patients who are more fragile than those under SC biotherapies. The differences in patient's characteristics could lead to a greater cost in the infliximab subgroup, but that bias is likely to be limited in this study because all biotherapies are indicated to treat RA at the same stage [10]. The choice of the practitioner to treat with either IV or SC biotherapies is more based on patient's comprehension of his condition and possible adherence to treatment than on a potential frailty. Moreover, a further qualitative analysis of consumption of the medication was carried out and confirmed there was no difference in term of concomitant medication in patients treated with infliximab, adalimumab or etanercept.

\section{Conclusion}

The results showed that costs of RA management lies not only in the price of biotherapies, but also in the cost of hospitalisation of inpatient care. Treatment with infliximab was more costly than with adalimumab or etanercept. These findings are aligned with the beliefs of both national and international publications that demonstrate inpatient care is more expensive than outpatient care, primarily because of hospitalisation costs [12, 14-17]. If all RA patients treated with infliximab in Alsace throughout 2012 had switched to adalimumab or etanercept, the total cost savings would have reached $€ 250,000$ at a regional level. Extrapolating to the whole country population, the annual cost saving could be more than $€ 8.3$ million. However, even if the study provides strong evidence that infliximab is more expensive than adalimumab or etanercept, final conclusions have to be made in the light of additional concepts such as the notion of quality of life, and some further studies are needed to prove outpatient care is indeed the most cost-effective way to treat RA patients.

Recent market approval of biosimilar medicines will lead to a repositioning of the different RA biotherapy management pathways. For instance, biosimilar infliximab has obtained its European marketing authorisation for RA in September 2013, and its cost should be about $30 \%$ lower than the non biosimilar compound [29]. Likewise, tofacitinib, an oral treatment approved in more than 20 countries, could significantly affect RA patients' management. The medico-administrative databases should provide an effective support to better evaluate the changes brought by the latest innovations and to shed a new light on questions related to the reduction of healthcare expenses.

Acknowledgments The authors are grateful to Pascal Lallemand, Pascale Willem and Bérangère Pierre for extracting the anonymised and aggregated data, to Sylvie Fontanel, Daouda Camara and Catherine Lukasek for support with the design of the study, and to Rama Piotto for proofreading and linguistic review of the manuscript.

\section{Compliance with Ethical Standards}

Funding This research received no specific grant from any funding agency in the public, commercial or not-for-profit sectors.

Conflict of interest Dr. Sordet received lecture/speaker fees, fees for expert opinion and travel expenses, and was involved in clinical trials with MSD, BMS, Roche, Abbvie, and Pfizer. The other authors have nothing to disclose.

Ethical approval The authors state that no ethical approval was needed.

Open Access This article is distributed under the terms of the Creative Commons Attribution-NonCommercial 4.0 International License (http://creativecommons.org/licenses/by-nc/4.0/), which permits any noncommercial use, distribution, and reproduction in any medium, provided you give appropriate credit to the original author(s) and the source, provide a link to the Creative Commons license, and indicate if changes were made.

\section{References}

1. Smolen JS, Landewé R, Breedveld FC, et al. EULAR recommendations for the management of rheumatoid arthritis with synthetic and biological disease-modifying antirheumatic drugs: 2013 update. Ann Rheum Dis. 2014;73(3):492-509.

2. Scottish Intercollegiate Guidelines Network. Management of early rheumatoid arthritis. A national clinical guideline 123 . Edinburgh: SIGN; 2011. http://www.sign.ac.uk/pdf/sign123.pdf. Accessed 1 Aug 2014.

3. American College of Rheumatology, Singh JA, Furst DE, Bharat A, Curtis JR, Kavanaugh AF, et al. 2012 Update of the 2008 American College of Rheumatology recommendations for the use of disease-modifying antirheumatic drugs and biologic agents in the treatment of rheumatoid arthritis. Arthritis Care Res. 2012;64(5):625-39.

4. National Institute for Health and Clinical Excellence. Adalimumab, etanercept and infliximab for the treatment of rheumatoid arthritis. London: NICE; 2010. http://www.nice.org.uk/ nicemedia/pdf/TA130guidance.pdf. Accessed 1 Aug 2014.

5. GUIPCAR group. Update of the clinical practice guideline for the management of rheumatoid arthritis in Spain. Madrid: Spanish Society of Rheumatology; 2007. p. 301.

6. Jönsson B, Kobelt G, Smolen J. The burden of rheumatoid arthritis and access to treatment: uptake of new therapies. Eur $\mathbf{J}$ Health Econ. 2008;8(Suppl2):S61-86.

7. Kavanaugh A. Economic consequences of established rheumatoid arthritis and its treatment. Best Pract Res Clin Rheumatol. 2007;21(5):929-42.

8. Modena V, Bianchi G, Roccatello D. Cost-effectiveness of biologic treatment for rheumatoid arthritis in clinical practice: an achievable target? Autoimmun Rev. 2013;12:835-8. 
9. Or Z. Implementation of DRG Payment in France: Issues and recent developments. Health Policy. 2014;117:146-50.

10. European Medicines Agency (EMA): European public assessment reports. http://www.ema.europa.eu/ema/index.jsp?curl= pages/medicines/landing/epar_search.jsp\&mid=WC0b01ac05800 1d124. Accessed 1 Aug 2014.

11. European Commission: Employment, social affairs and inclusion: your rights country by country: your social security rights in France. http://ec.europa.eu/social/main.jsp?catId=858. Accessed 1 Aug 2014.

12. Maravic M. Economic impact of rheumatoid arthritis (RA) biotherapies in France. Jt Bone Spine. 2010;77:319-24.

13. Maravic M, Baudens G, Sanchez JP, et al. Biotherapy and rheumatoid arthritis: a medico-economic evaluation from 2008 French Hospital Database. Jt Bone Spine. 2012;79:94-102.

14. Schabert VF, Watson C, Joseph GJ, Iversen P, Burudpakdee C, Harrison DJ. Costs of tumor necrosis factor blockers per treated patient using real-world drug data in a managed care population. J Manag Care Pharm. 2013;19(8):621-30.

15. Bonafede MM, Gandra SR, Watson C, et al. Cost per treated patient for etanercept, adalimumab, and infliximab across adult indications: a claims analysis. Adv Ther. 2012;29(3):234-48.

16. Bonafede M, Joseph GJ, Shah N, et al. Cost of tumor necrosis factor blockers per patient with rheumatoid arthritis in a multistate Medicaid population. Clinicoecon Outcomes Res. 2014;15(6):381-8.

17. Joyce AT, Gandra SR, Fox KM, et al. National and regional dose escalation and cost of tumor necrosis factor blocker therapy in biologic-naïve rheumatoid arthritis patients in US health plans. J Med Econ. 2014;17(1):1-10.

18. Rubio-Terrés C, Ordovás Baines JP, Pla Poblador R, et al. Use and cost of biological disease-modifying anti-rheumatic drugs in Spain (PRAXIS study). Farm Hosp. 2007;31(2):78-92.

19. Zeidler J, Mittendorf T, Müller R, et al. Biologic TNF inhibiting agents for treatment of inflammatory rheumatic diseases: dosing patterns and related costs in Switzerland from a payers perspective. Health Econ Rev 2012;2(1):20.

20. Guillemin F, Saraux A, Guggenbuhl P, et al. Prevalence of rheumatoid arthritis in France: 2001. Ann Rheum Dis. 2005;64(10):1427-30.
21. Roux CH, Saraux A, Le Bihan E, et al. Rheumatoid arthritis and spondyloarthropathies: geographical variations in prevalence in France. J Rheumatol. 2007;34(1):117-22.

22. Biver E, Beage V, Verloop D, et al. Low and stable prevalence of rheumatoid arthritis in northern France. Jt Bone Spine. 2009;76:497-500.

23. Sany J, Bourgeois P, Saraux A, et al. Characteristics of patients with rheumatoid arthritis in France: a study of 1109 patients managed by hospital based rheumatologists. Ann Rheum Dis. 2004;63:1235-40.

24. Site Réseau d'Evaluation en Economie de la Santé (REES): congrès SFR Paris 2010: Launois R, Le Moine JG, Huynh MT, Boissier MC. Efficacité et tolérance des traitements de la polyarthrite rhumatoïde étudiés par méta-analyse hiérarchique bayésienne. Combinaison simultanée des résultats relevés dans les essais randomisés et les études observationnelles avec groupe contrôle. http://www.rees-france.com/article.php3?id_article $=744$ \&var_recherche=polyarthrite. Accessed 1 Aug 2014.

25. Chen YF, Jobanputra P, Barton P, et al. A systematic review of the effectiveness of adalimumab, etanercept and infliximab for the treatment of rheumatoid arthritis in adults and an economic evaluation of their cost-effectiveness. Health Technology Assessment 2006;10(42):iii-iv,xi-xiii, 1-229.

26. Nam JL, Ramiro S, Gaujoux-Viala C, et al. Efficacy of biological disease-modifying antirheumatic drugs: a systematic literature review informing the 2013 update of the EULAR recommendations for the management of rheumatoid arthritis. Ann Rheum Dis. 2014;73(3):516-28.

27. Mariette $X$, Gottenberg JE, Ravaud $P$, et al. Registries in rheumatoid arthritis and autoimmune diseases: data from the French registries. Rheumatology. 2011;50:222-9.

28. Haut Conseil de la santé publique. Pour une meilleure utilisation des bases de données administratives et médicoadministratives nationales pour la santé publique et la recherche. Paris:HCSP; 2012. p. 56. http://www.hcsp.fr/Explore.cgi/avisrapportsdomaine ?clefr=258. Accessed 1 Aug 2014.

29. Haustein R, De Millas C, Höer A, et al. Saving money in the European healthcare systems with biosimilars. Generics Biosimilars Initiat J (GaBI Journal). 2012;1(3-4):120-6. 